\title{
DIURNAL VARIATIONS IN THE GRAZING OF PLANKTONIC COPEPODS
}

\author{
By D. T. Gauld \\ Marine Station, Millport \\ (Text-figs. I-3)
}

Wimpenny (1938) has shown that the percentage of copepods taken in the sea with food in the gut tends to be higher at night than by day. Most planktonic animals perform diurnal vertical migrations, of greater or less extent. Wimpenny's observations may well be a consequence of such migrations.

On the other hand, during investigations into grazing rate of planktonic copepods (Fuller, I937; Gauld, I95I) some of the measurements have suggested that there is a diurnal variation in the rate at which the copepods collect their food, even under laboratory conditions when migration is impossible, and that they filter the water more quickly at night than by day. The variation in the percentage of copepods containing food may be caused simply by changes in the rate of feeding, this being controlled either by the amount of light in their environment or by some internal rhythm affecting their behaviour.

An investigation of diurnal variations in the feeding behaviour of Calanus finmarchicus (Gunn.) was undertaken to investigate (i) its behaviour in nature, and (ii) the possible existence of alternations of feeding and resting periods under laboratory conditions. This species was chosen because it is the dominant copepod species in the Clyde sea area, is readily obtainable in reasonable numbers at all times of the year, and has already been the subject of investigation of feeding rate.

\section{FieLd OBSERvations \\ Methods}

Calanus were obtained from I0-min. hauls of $50-\mathrm{cm}$. coarse tow-nets (26 meshes to the inch) taken at 4-hourly intervals through $24 \mathrm{hr}$. Three nets were fished at once, 25 fathoms apart on a trawl warp, to the end of which was attached a cable depressor (Barnes, 195I). Rigged in this way, the uppermost net fished $2-3 \mathrm{~m}$., the second $35-40 \mathrm{~m}$. and the lowest $c$. $75-80 \mathrm{~m}$. from the surface. There was no means of closing the nets before hauling, but the percentage of the fishing time spent by the lower nets in the upper strata was small and unlikely to have interfered greatly with the results. The hauls were taken at a station just outside Tarbert, Loch Fyne. At this station deep water 
( $170 \mathrm{~m}$.) was available only half a mile from the harbour where the research vessel could be tied up in harbour, and examination of the animals begun within $20 \mathrm{~min}$. of their capture.

As Wimpenny (1937) has pointed out, the gut contents of Calanus are usually very easily observed, and in these investigations were estimated on the living animals as soon as possible after capture. Thirty to forty Calanus were transferred from the catch to a Petri dish and most of the water withdrawn so that the animals were compelled to lie on their sides and for the most part motionless. They were then examined under a low-power microscope and the amount of food in the gut recorded. This method of examination was adopted because it was found that in fixed catches, a variable and sometimes important fraction of the animals defaecated when formalin was added to the catch, and it was thought desirable to reduce as much as possible the interval between capture and examination. The number of animals examined varied from haul to haul, but an attempt was made to examine at least fifty, and, if time and numbers permitted, Ioo of both Stage V and adult female Calanus. Occasionally Stage IV was sufficiently numerous for significant numbers to be counted in addition to the larger stages. After this had been done the catches were fixed with formalin and brought back to the laboratory. In some of the hauls the total numbers of Calanus or the numbers of one or other stage were too small for counts to be made quickly on board ship and supplementary counts of fixed material were made in the laboratory.

- I am indebted to Skipper R. E. Souter and the crew of M.F.V. Calanus for their willing co-operation in taking the $24-\mathrm{hr}$. stations which comprise the field observations to be recorded here.

\section{Results}

Before anything is said about the gut contents of the catches, some remarks must be made about the vertical distribution of the animals. Since closing nets were not used the catches of the bottom net may have been made partly in the upper waters, but the differences in distribution to which attention are to be drawn are too marked to be attributed entirely to this cause, and in any case concern primarily the top net. The tables do not give the total numbers of animals caught (which were never estimated), but on any one occasion the catches of the top net were either of more or less the same size throughout the $24 \mathrm{hr}$. or else there was a marked difference between catches made in daylight and darkness so that the general picture of diurnal changes in distribution given Tables I and II is a true one.

It can be seen from the tables that only on seven of the thirteen occasions on which hauls were taken, were the catches of the top net distinctly greater in darkness than in daylight, while on I7 April and II September 1950, large catches of Calanus were taken at the surface throughout the $24 \mathrm{hr}$. On the four remaining occasions the catches varied rather irregularly and cannot be 
looked on as clear evidence for or against vertical movements. It is remarkable that clear evidence of migration was obtained only on two occasions in 1950 (Io July and 2I November), and even on Io July the vertical movements were not so clear cut as those of I95I, while in I95I surface hauls in daylight were always blank except in April and May. The presence of adult and Stage V Calanus in the surface water during daylight in spring and early summer has already been recorded for the Clyde (Brook, I886; Marshall \& Orr, I927; Nicholls, 1933; Marshall, Nicholls and Orr, 1934), but it seems that a much larger percentage of the population than usual was present in the surface waters in daylight on Io April, and also on II September 1950, when exceptionally large catches were taken in daylight, although the day was not unusually dull.

\section{Adult Females}

The details of the observations on adult females are given in Table $\mathrm{I}$, in which the numbers examined from each haul and the percentage of these which contained food is given. If a haul was taken and no Calanus seen this is given as (0) $)_{0}$; if a haul was not taken or was lost, it is indicated by a dash. The times are given by the $24-\mathrm{hr}$. clock and are always Greenwich mean time.

The data of Table I are summarized in Table II, from which it can be seen that the percentage of adult female Calanus found to contain food was practically identical in daylight and in darkness. These figures quite clearly furnish no evidence of diurnal rhythm in feeding.

On the other hand, adult female Calanus were caught in all twenty-two surface hauls taken in the dark, but only in twenty-seven out of the forty-eight daylight hauls. ${ }^{1}$ In consequence, more adult females were found containing food by night (I275) than by day (I04I), in spite of the fact that there were more than twice as many daylight hauls as night hauls. These observations then agree with those of Wimpenny (1938) that the feeding of Calanus takes place mostly at night, but they also show that the reason for this is that by day Calanus is usually absent from the surface water where their food is principally found.

The numbers of female Calanus containing food in the deeper nets was nearly always less than in the surface net, the lowest net of the three showing the smallest percentage containing food. Of the adult females taken on all occasions, $68 \%$ of those in the middle net and $46.5 \%$ of those in the lowest net contained food compared with $86 \%$ in the surface net. The percentage of animals containing food varied considerably from one series of hauls to another-the mean for the bottom net from I6\% (9. i. 5I) to $75 \%$ (I2. v. $5 \mathrm{I}$ ), that of the mid net from $30 \%$ (9. i. 5 I) to $86 \%$ (28. ii. 50)-but in any given series there is no obvious pattern in the occurrence of food in the guts unless

1 The hauls at 16.00 and $08.00 \mathrm{hr}$. were always taken in daylight, those at 20.00 and $04.00 \mathrm{hr}$. in daylight from May to August, and in darkness in the other months. 
there is clear evidence of vertical migration, when more of the copepods in the lower nets tended to have food in the gut at midnight and 4 o'clock than they had before midnight.

\section{Table I. Females: Percentage with food}

(The figures in suffix give the numbers examined.)

\begin{tabular}{|c|c|c|c|c|c|c|c|}
\hline $\begin{array}{l}\text { Time (hr.)... } \\
28 \text {. ii. } 50\end{array}$ & . 12.00 & I6.00 & 20.00 & 24.00 & 04.00 & 08.00 & 12.00 \\
\hline $\begin{array}{l}\text { 28. ii. } 50 \\
\text { Top } \\
\text { Mid } \\
\text { Bottom }\end{array}$ & $\begin{array}{c}83_{6} \\
100_{7} \\
69_{88}\end{array}$ & $\begin{array}{l}89_{249} \\
9 \mathrm{I}_{100} \\
6 \mathrm{I}_{100}\end{array}$ & $\begin{array}{l}9454 \\
75_{98} \\
85_{102}\end{array}$ & $\begin{array}{l}75_{8} \\
88_{100} \\
8474\end{array}$ & $\begin{array}{l}98_{100} \\
89_{100} \\
8 \mathrm{I}_{100}\end{array}$ & $\begin{array}{l}90_{21} \\
87_{23} \\
57_{100}\end{array}$ & $\begin{array}{l}69_{13} \\
83_{12} \\
82_{100}\end{array}$ \\
\hline $\begin{array}{l}\text { I7. iv. } 50 \\
\text { Top } \\
\text { Mid } \\
\text { Bottom }\end{array}$ & $\begin{array}{l}99_{100} \\
72_{100} \\
52_{100}\end{array}$ & $\begin{array}{l}89_{100} \\
69_{100} \\
24100\end{array}$ & $\begin{array}{l}9 \mathrm{I}_{100} \\
6 \mathrm{I}_{100} \\
45_{100}\end{array}$ & $\begin{array}{l}96_{100} \\
75_{100} \\
28_{100}\end{array}$ & $\begin{array}{l}92_{100} \\
48_{50} \\
56_{95}\end{array}$ & $\begin{array}{l}98_{67} \\
65_{79} \\
36_{100}\end{array}$ & $\begin{array}{l}86_{100} \\
64_{98} \\
5 I_{100}\end{array}$ \\
\hline $\begin{array}{l}\text { 29. v. } 50 \\
\text { Top } \\
\text { Mid } \\
\text { Bottom }\end{array}$ & $\begin{array}{c}\mathrm{IOO}_{5} \\
48_{50} \\
3450\end{array}$ & $\begin{array}{c}\mathrm{IOO}_{2} \\
72_{50} \\
5450\end{array}$ & $\begin{array}{l}\mathrm{IOO}_{4} \\
62_{50} \\
6450\end{array}$ & $\begin{array}{c}\mathrm{IOO}_{4} \\
96_{50} \\
6450\end{array}$ & $\begin{array}{l}\mathrm{IOO}_{1} \\
6450 \\
56_{50}\end{array}$ & $\begin{array}{c}\mathrm{IOO}_{3} \\
76_{50} \\
6450\end{array}$ & $\begin{array}{l}(0)_{0} \\
84_{50} \\
44_{50}\end{array}$ \\
\hline $\begin{array}{l}\text { I0. vii. } 50 \\
\text { Top } \\
\text { Mid } \\
\text { Bottom }\end{array}$ & $\begin{array}{c}29_{14} \\
\mathrm{O}_{8} \\
39_{100}\end{array}$ & $\begin{array}{r}(\mathrm{O})_{0} \\
4 \mathrm{O}_{10} \\
-\quad 4 \mathrm{O}_{83}\end{array}$ & $\begin{array}{l}676 \\
32_{50} \\
69_{100}\end{array}$ & $\begin{array}{l}83_{18} \\
9 I_{70} \\
8451\end{array}$ & $\begin{array}{l}(0)_{0} \\
43_{100} \\
799_{100}\end{array}$ & $\begin{array}{l}5 \mathrm{O}_{2} \\
48_{50} \\
26_{100}\end{array}$ & $\begin{array}{l}\mathrm{O}_{2} \\
12 \cdot 58 \\
2 \mathrm{O}_{20}\end{array}$ \\
\hline $\begin{array}{l}\text { II. ix. } 50 \\
\text { Top } \\
\text { Mid } \\
\text { Bottom }\end{array}$ & $\begin{array}{l}78_{100} \\
57_{100} \\
2 \mathrm{I}_{100}\end{array}$ & $\begin{array}{l}9 \mathrm{I}_{100} \\
64_{100} \\
24100\end{array}$ & $\begin{array}{r}78_{100} \\
68_{100} \\
40_{100}\end{array}$ & $\begin{array}{l}88_{100} \\
77_{100} \\
36_{100}\end{array}$ & $\begin{array}{l}73_{100} \\
82_{100} \\
29100\end{array}$ & $\begin{array}{c}74_{100} \\
7 \mathrm{I}_{100} \\
\end{array}$ & $\begin{array}{l}92_{100} \\
70_{100} \\
30_{100}\end{array}$ \\
\hline 21. xi. 50 & & & No fe & es seen. & & & \\
\hline $\begin{array}{l}\text { 9. i. 5I } \\
\text { Top } \\
\text { Mid } \\
\text { Bottom }\end{array}$ & $\begin{array}{l}(\mathrm{O})_{0} \\
\mathrm{O}_{3} \\
\mathrm{O}_{14}\end{array}$ & $\begin{array}{l}(0)_{0} \\
2_{100} \\
0_{100}\end{array}$ & $\begin{array}{l}84_{19} \\
34_{83} \\
\mathrm{I}_{100}\end{array}$ & $\begin{array}{l}68_{19} \\
48_{101} \\
\mathrm{I} 2_{106}\end{array}$ & $\begin{array}{l}55_{9} \\
77_{22} \\
{ }^{6} 6_{31}\end{array}$ & $\begin{array}{l}\mathrm{IOO}_{1} \\
36_{11} \\
\mathrm{I} 8_{100}\end{array}$ & $\begin{array}{l}(\mathrm{O})_{0} \\
\mathrm{O}_{19} \\
\mathrm{O}_{3}\end{array}$ \\
\hline $\begin{array}{l}\text { I4. ii. 5I } \\
\text { Top } \\
\text { Mid } \\
\text { Bottom }\end{array}$ & $\begin{array}{l}(0)_{0} \\
(0)_{0} \\
17_{17}\end{array}$ & E & $\begin{array}{l}99_{100} \\
85_{100} \\
\mathrm{I} 3100\end{array}$ & $\begin{array}{l}99_{71} \\
94109 \\
33_{100}\end{array}$ & $\begin{array}{l}99_{110} \\
83_{41} \\
18_{100}\end{array}$ & $\begin{array}{l}(0)_{0} \\
449_{9} \\
82_{82}\end{array}$ & $\begin{array}{r}(0)_{0} \\
1_{315} \\
452\end{array}$ \\
\hline $\begin{array}{l}\text { I4. iii. } 5 \text { I } \\
\text { Top } \\
\text { Mid } \\
\text { Bottom }\end{array}$ & $\begin{array}{l}\mathrm{IOO}_{3} \\
8 \mathrm{O}_{6} \\
63_{94}\end{array}$ & $\begin{array}{l}(0)_{0} \\
25_{4} \\
47_{100}\end{array}$ & $\begin{array}{r}80_{5} \\
0_{5} \\
36_{44}\end{array}$ & $\begin{array}{c}\mathrm{IOO}_{5} \\
86_{35} \\
50_{44}\end{array}$ & $\begin{array}{l}82_{43} \\
68_{71} \\
33_{100}\end{array}$ & $\begin{array}{c}\mathrm{IOO}_{1} \\
74_{23} \\
\mathrm{O}_{3}\end{array}$ & $\begin{array}{l}\mathrm{IOO}_{3} \\
6 \mathrm{O}_{5} \\
4 \mathrm{O}_{20}\end{array}$ \\
\hline
\end{tabular}

5. iv. $5 \mathrm{I}$

7. v. $5 I^{\star}$

Top
Mid
Bottom

$98_{62}$

Very few : top, $78_{18}$; mid, $63_{11}$; bottom, $72_{82}$

4. 7. 5 I

Top

Mid

$\frac{98_{62}}{76_{100}}$

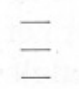

$\frac{90_{41}}{72_{100}}$

85100

二

$\frac{86_{100}}{67_{100}}$

(o) 0

(o)

$\mathrm{O}_{3}$

$2 \mathrm{O}_{25}$

(o) 0

Bottom

(o) 0

$30_{50}$

4450

$42_{50}$

$\mathrm{IOO}_{60}$
$96_{50}$

8450

$82_{90}$

(o) $)_{0}$

(o)

$(\mathrm{o})_{0}$

I5. viii. 5 I

Top

(o) 0

(o) 0

(o) 0

9450
$100_{50}$
$78_{50}$

(0) 0

$76_{60}$
8450

$(0)_{0}$
$76_{50}$
450

(0) 0

9450

Bottom $\quad 1650$

6250
4425

$62_{50}$
$18_{50}$

$78_{50}$

$38_{50}$

* The series on 17 May I95I was taken off L. Ranza and is incomplete: only two nets were used and the times of the hauls were $13.00,19.00,22.00$ and $07.30 \mathrm{hr}$. 


\section{TABLE II}

$\begin{array}{lccc}\text { No. } & \begin{array}{c}\text { No. with } \\ \text { food }\end{array} & \begin{array}{c}\text { Percentage } \\ \text { with } \\ \text { food }\end{array} \\ \text { Daylight } & \text { II90 } & \text { I04I } & 87.5 \\ \text { Darkness } & \text { I5I4 } & \text { I275 } & 84 \\ \text { Total } & 2704 & 2316 & 86\end{array}$

The decrease in the numbers of Calanus with food in the gut in deeper water and its dependence on the stratification of the food organisms was more clearly demonstrated on II September 1950 when a more detailed series of hauls was taken at six depths, and water samples taken at roughly corre-

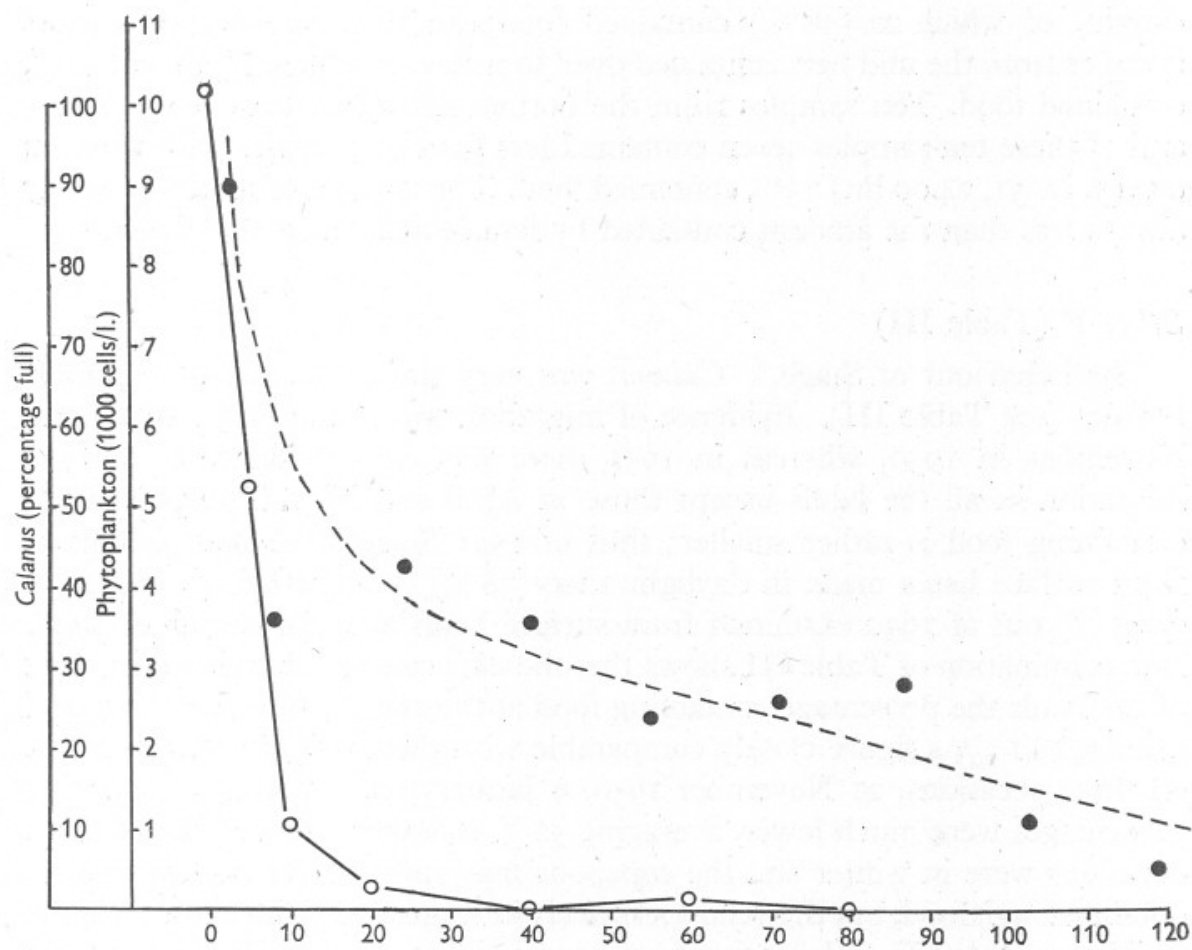

Fig. I. Percentage of Calanus with food and phytoplankton concentration. Symbols: and broken line, percentage of Calanus with food; $\bigcirc$ and full line, phytoplankton concentration. Horizontal scale: depth in metres (O-I2O).

sponding depths to show the distribution of the phytoplankton. The results are illustrated in Fig. I in which the phytoplankton (I000's of cells/litre) and the percentage of Calanus with food are both graphed against depth. It can 
be seen that the phytoplankton was concentrated in a narrow stratum about Io $\mathrm{m}$. deep, in which $90 \%$ of the Calanus were full; below this stratum the percentage fell from c. $40 \%$ at $10 \mathrm{~m}$. to $5 \%$ at $100 \mathrm{~m}$.

\section{Adult Males}

Male Calanus were not found in most of the hauls in sufficient numbers to obtain a clear picture of their behaviour. In addition they are relatively opaque and any food they may contain is less easy to see, so possibly small quantities of food, particularly in the anterior part of the gut, were overlooked.

Of the 1555 adult males examined from all the catches $63 \%$ were in the lowest net, and $62 \%$ of them were empty. On only one occasion were more than twenty-five taken in a surface net (I8. iv. $50,08.00 \mathrm{hr}$.) when 38 were caught, of which $22(58 \%)$ contained food; on the same occasion three samples from the mid nets contained over 50 males, of which 45,73 and $44 \%$ contained food. Ten samples from the bottom net contained over 50 males and of these ten samples seven contained less than $40 \%$ males with food; in one (5. iv. 5I, $24.00 \mathrm{hr}$.) $73 \%$ contained food. The amount of food was nearly always less than the amount contained by female and Stage V Calanus.

\section{Stage $V$ (Table III)}

The behaviour of Stage V Calanus was very similar to that of the adult females (see Table III). Evidence of migration was found only in July and November in 1950, whereas in 195I there was clear evidence of vertical migration in all the hauls except those in April and May. The percentage containing food is rather smaller; thus of I54I Stage V Calanus examined from surface hauls made in daylight I200 (78\%) contained food, and II 8 I $(72.5 \%)$ out of 1630 examined from surface hauls at night contained food. But examination of Table III shows that the data can be subdivided: in most of the hauls the percentage containing food at the surface was over $70 \%$ and averaged $8 \mathrm{I} \%$, a figure closely comparable with that for adult females. But on three occasions, 2I November 1950, 9 January and I5 August I95I, the percentages were much lower, averaging $50 \%$ containing food. Two of these occasions were in winter and the copepods may simply have been unable to obtain enough food, but this seems less likely in August, and since from August to January Stage V Calanus form an overwintering population it is possible that the small percentage containing food is due to a real change.in behaviour.

On I I September 1950, the percentages containing food were also abnormally low at night, averaging only $3 \mathrm{I} \%$ in agreement with the other observations in autumn. But on this occasion Calanus were present at the surface in considerable numbers during the day and of those taken by day at the surface $82 \%$ contained food, a percentage comparable to those found in spring and summer catches. The behaviour shown by the Calanus here is exactly the 
opposite of what would normally be expected because most of them were apparently feeding by day and not at night.

\section{Table III. Stage V: Percentage with Food}

(The figures in suffix give the numbers examined.)

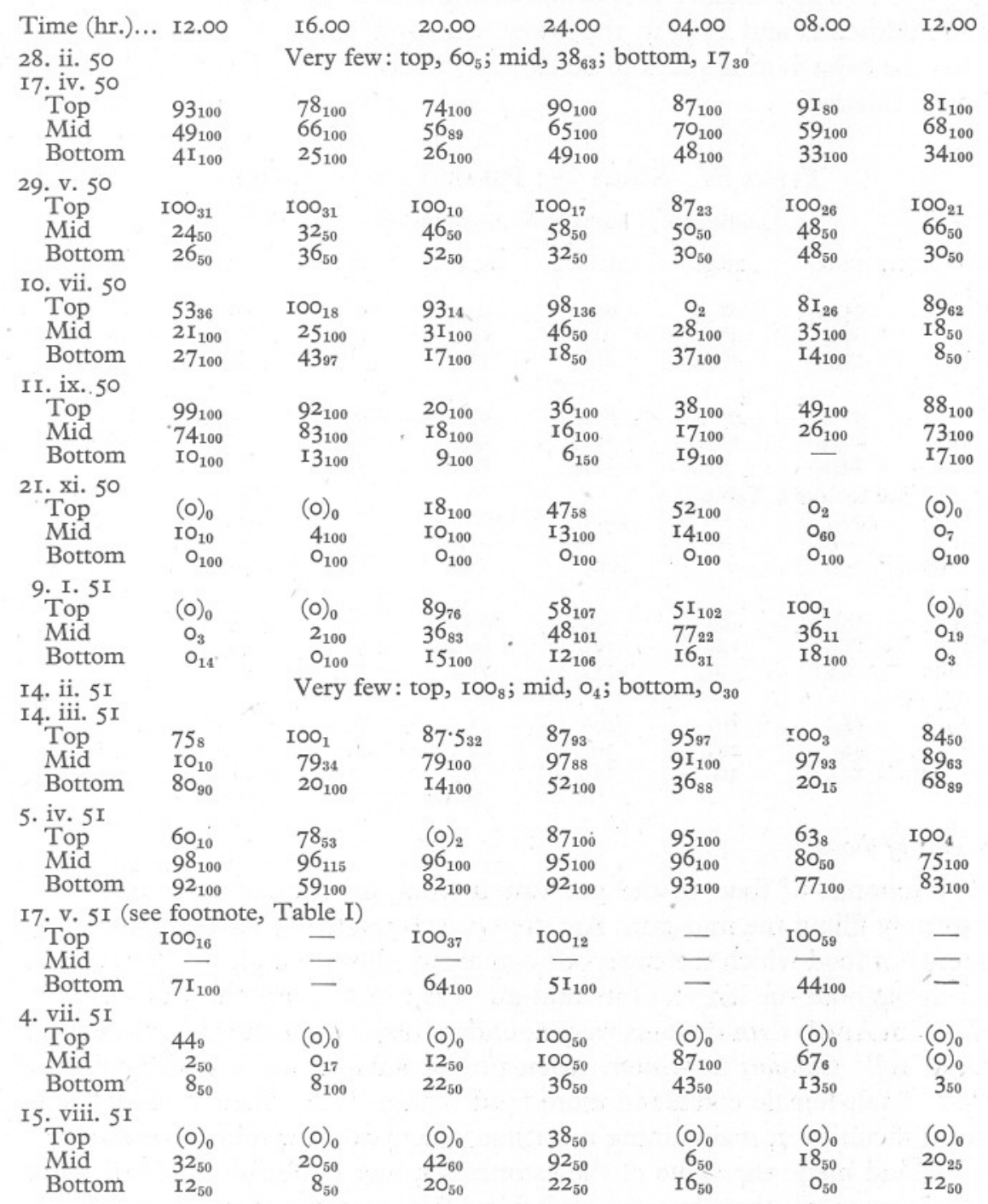

The percentage containing food in the lower nets, as with adult females, was less than at the surface, averaging $46 \%$ in the middle net and $29 \%$ in the lowest net. 


\section{Stage IV (Table IV)}

On a few occasions, for instance on 29 May I950, fair numbers of Stage IV were caught. When the numbers were sufficiently large to give significant counts, most of those in the surface water (averaging 91 \% for all the samples in Table IV) and a smaller proportion of those from the deeper layers ( $38 \%$ in the middle net and $23 \%$ in the lowest net from Table IV) contained food, so that the behaviour appears to be closely similar to that of adult female and Stage V Calanus.

\section{Table IV. Stage IV: Percentage with food}

(The figures in suffix give the numbers examined.)

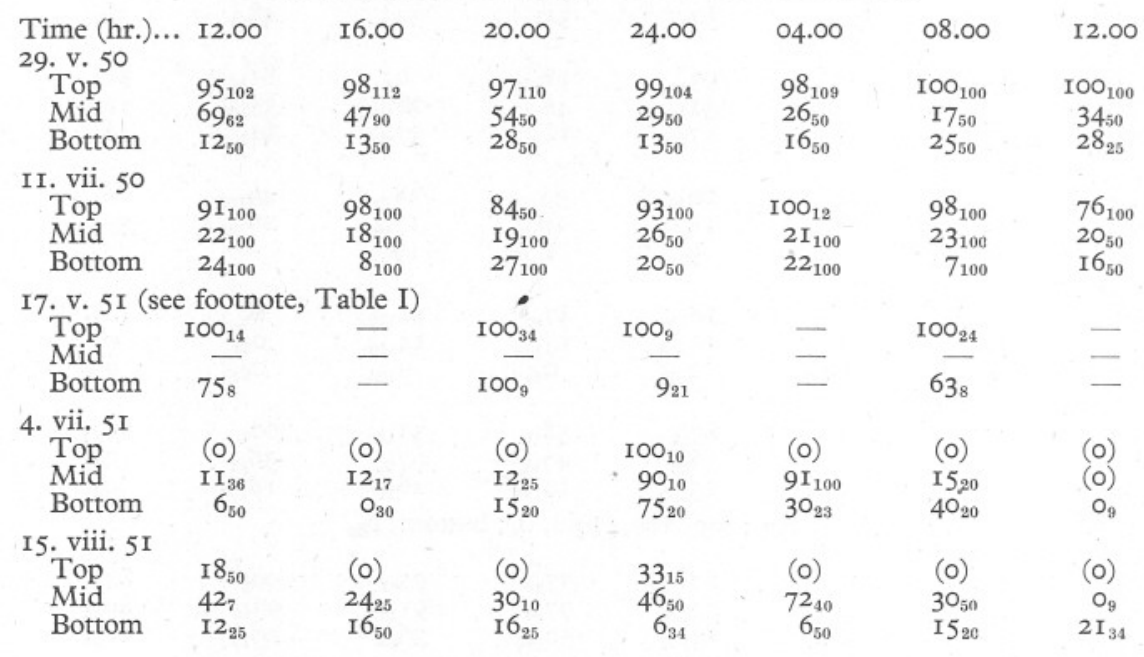

\section{Amount of Food}

The amount of food in the gut varied from small quantities to a mass completely filling the mid-gut. An attempt was made to record the different amounts of food which the copepods contained. For example a Calanus with food throughout the length of its mid-gut was recorded as 'full', but a 'full' Calanus in April when diatoms were abundant obviously contained more food than a 'full' Calanus in winter, when phytoplankton was scarce; similarly, a 'full' adult female contained more food than a 'full' Stage V. These and other difficulties in maintaining a constant standard in a subjective estimate of this kind made the value of the estimates rather doubtful. The following general statements, however, are probably a fair summary of the observations.

The amount of food contained in the guts of the copepods with food was greatest in spring (April, May) when nearly all would be packed with food. During the summer the Calanus were not quite so well filled, but in winter 
the quantity was distinctly less, and small even in many animals at the surface. The amount of food in individuals captured in the lowest net was nearly always less than that found at the surface: for instance copepods with packed guts were rarely seen in the deepest catches. The Calanus in the middle net were in an intermediate condition; when food was abundant, most would contain a large amount of food, but at other times the amount might be distinctly less than at the surface. As would be expected from their sizes, females contained in general rather more than Stage V and these distinctly more than Stage IV; males contained much less for their size than any of the other stages and in general contained distinctly less than Stage V.

Calanus finmarchicus and $\mathrm{C}$. helgolandicus

Rees (I949) has drawn attention to the existence of two possible subspecies of $C$. finmarchicus and has suggested that they differ in temperature tolerance. Marshall \& Orr (1952) have recorded the presence of $C$. helgolandicus in the Clyde, occasionally in fair numbers, and have shown that the two forms differ in the time of spawning. It would be interesting to see whether its feeding behaviour is also different. The catches were accordingly examined to see if any $C$. helgolandicus were present, but, except on one occasion, II September I950, this form was absent altogether or made up an extremely small fraction 'of the catch. So far as could be seen from these small numbers the feeding behaviour of the two forms was identical. It has already been seen that the conditions in September I950 were unusual and the presence of $C$. helgolandicus might explain the abnormality, but the numbers of $C$. helgolandicus do not vary very much from one haul to another, and since they did not rise above $32 \%$ of any catch, they are too few in number to account for the large changes in feeding behaviour observed. Further, the percentage of $C$. helgolandicus containing food did not differ significantly from that of $C$. finmarchicus.

\section{LABORATORY OBSERVATIONS}

\section{Methods}

In the laboratory the existence of a possible periodicity in grazing rate was investigated, as in the field observations by direct examination of the gut contents. The copepods were kept in a suspension of a food organism, usually a species of Chlamydomonas (cf. Gauld, I95I), and examined from time to time, usually at intervals of $4 \mathrm{hr}$., and the amount of food recorded.

\section{Preliminary Investigations Results}

Before the other experiments and any field observations were started, a number of experiments were made to see how long a copepod would take to fill its gut when it began to feed and how long it would remain full after it had ceased feeding. The former were done by keeping copepods in sterile sea 
water for some hours, usually overnight, to make sure they were empty. They were then put into suspensions of Chlamydomonas and examined at intervals of IO-I $5 \mathrm{~min}$. to see how full they were. It proved very difficult to get any satisfactory observations. The transference of the copepods from a beaker to a watch-glass for examination disturbed them, and when they were returned to the beakers some time might elapse before they settled down, during which they darted about the beaker rapidly and normal feeding would not take place. The time taken to settle down varied quite erratically. However, in a moderately thick suspension of Chlamydomonas, comparable to those used in the experiments, Calanus can fill its gut in IO-I5 min. at most and in thicker suspensions in a very few minutes indeed. It is unlikely that the natural phytoplankton on which the Calanus examined in the field were feeding would ever be as rich as that used in the experiments except possibly at the height of the spring maximum, but even in suspensions comparable in density to natural phytoplankton Calanus can fill its gut in less than $30 \mathrm{~min}$.

To find out how long food could remain in the gut the exact opposite procedure was followed. A number of Calanus were kept for some time in a fairly thick suspension of Chlamydomonas until they were full. They were then transferred into sterile sea water and examined as before at short intervals. Although a very small quantity of food matter may remain for several hours in the gut of a copepod which is swimming in sterile sea water, the bulk of the food will be digested and the undigestible residue passed out in about $\mathrm{I}-2 \mathrm{hr}$.

\section{Twenty-four-Hour Experiments}

Observation of the amount of food in the gut gave no clear evidence of a consistent feeding rhythm, either for adult female or for Stage V Calanus. A typical series of observations is illustrated in Fig. 2. Each horizontal line illustrates the behaviour of an individual copepod and the vertical columns correspond to the hour of the observations. The quantity of food in the gut is given in an arbitrary scale-a column blacked to its full height means that the gut was quite full; three-quarters its height means that the anterior part of the gut was full but the posterior half was empty (usually because a faecal pellet had been passed out recently); half the height that the gut was only partly full, and one-quarter that only a small quantity of food was present. A white column means that the gut was empty.

It can be seen from the diagram that most of the adult females were feeding continuously throughout the $24 \mathrm{hr}$., the few drops in the columns were almost certainly due to the ejection of a faecal pellet just before examination. They were not, of course, perfectly consistent, as numbers 2 and 7 show. Stage V's (Fig. 3) seemed to be much less voracious and were much less predictable in their behaviour. Although feeding was not continuous and long gaps apparently intervened between meals, no consistent rhythm of feeding and resting can be deduced from these data. One point, however, emerges very plainly. 
Calanus can spend a long time in a dense suspension of food without feeding -some observations were carried on over several days, and although the

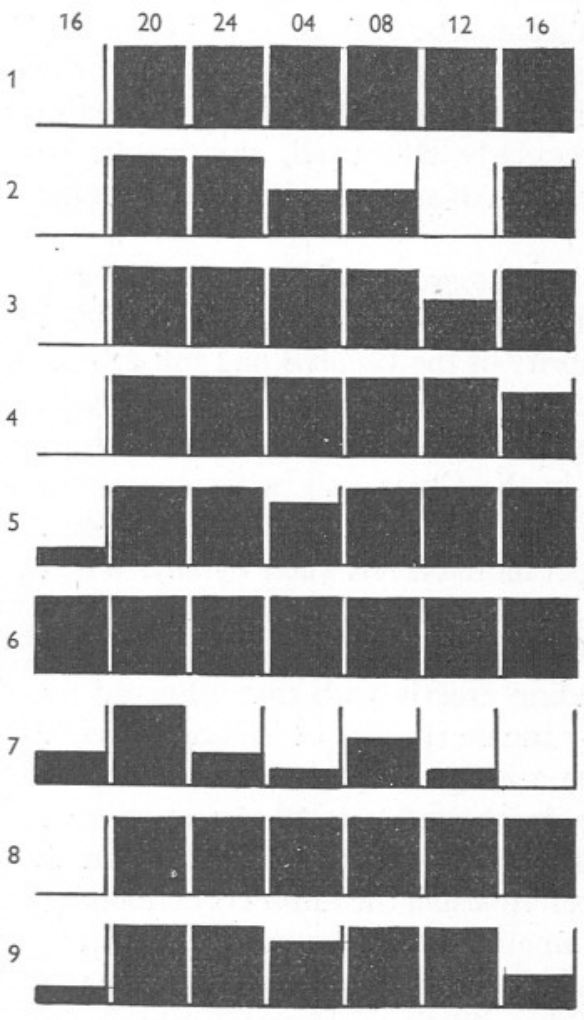

Fig. 2. Feeding of adult female Calanus. For explanation see text.

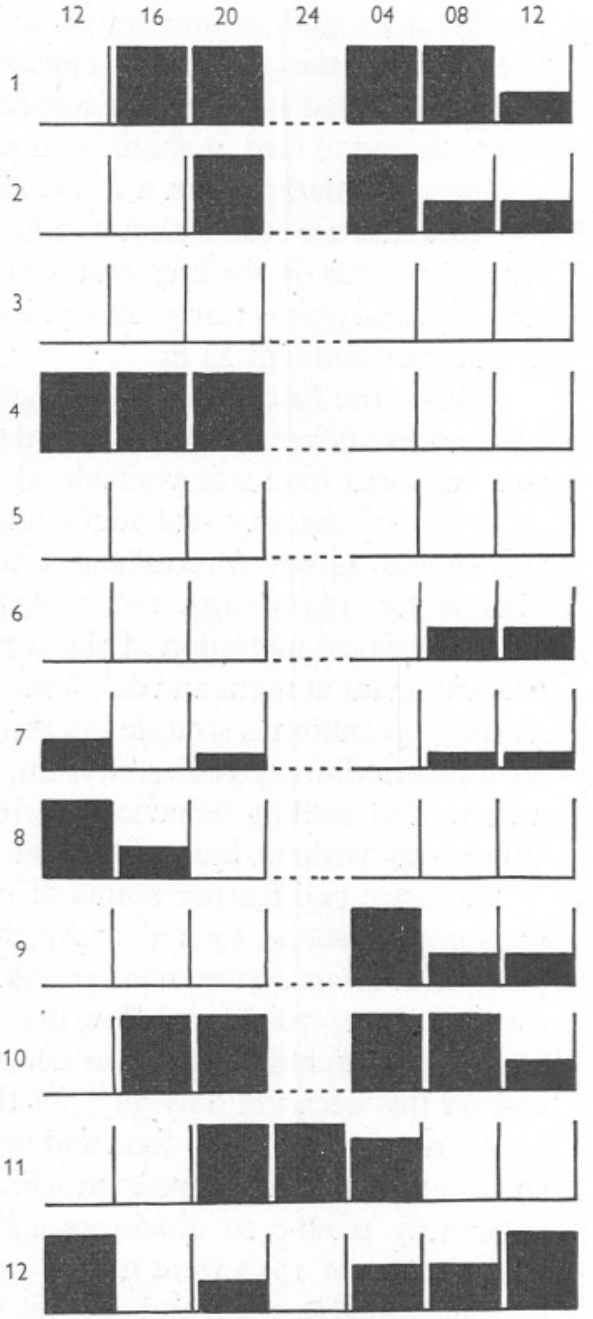

Fig. 3. Feeding of Stage V Calanus. For explanation see text. A broken line in $24 \mathrm{hr}$. column indicates that no observations were made at midnight.

copepod appeared to be perfectly healthy and was seen, at least on some occasions, swimming normally, no food was ever observed in the gut. 


\section{Discussion}

A copepod cannot be feeding, i.e. filtering water through its maxillae and ingesting the material accumulating on the maxillae, and yet have an empty gut for any length of time unless the water is nearly or absolutely barren. As the results of the preliminary experiments show, the gut fills up quite rapidly when a copepod is put into a suspension of food and, within an hour at most after starting to feed, it should contain sufficient food to make it clear that it is feeding. Similarly, when a full Calanus is put into barren water most of the gut contents are lost within $\mathrm{I}-2 \mathrm{hr}$. of the cessation of feeding. It is plain, therefore, that if feeding and resting regularly alternated, this would be detected and quite clearly defined by estimation of amount of the gut contents at intervals through $24 \mathrm{hr}$.

Neither the field observations nor the laboratory experiments provide any evidence whatever of a diurnal rhythm of this kind. On the contrary, provided that sufficient food was available, the majority of the Calanus had full guts at all hours of the day and night and apparently were feeding continuously throughout $24 \mathrm{hr}$. Alternation of feeding and non-feeding periods, such as Wimpenny (1938) suggested, took place in the Clyde only when there was marked vertical migration of the copepods, into the surface water where food was abundant at night and down into deepet more barren water by day. When the phytoplankton is stratified in this way, diurnal vertical migration produces an apparent diurnal feeding rhythm, as was seen on many occasions in I95Ia pattern of feeding behaviour corresponding exactly with that observed by Wimpenny without the postulation of any innate rhythm in feeding activity.

There are two further points of interest arising out of these observations. On some occasions, such as I7 April I950, no obvious vertical migration took place and Calanus were more or less evenly distributed at least as far down as the lowest net, $70-80 \mathrm{~m}$. below the surface. As usual the numbers containing food in the catches of the lower nets were smaller than those in the upper net, and on this occasion only $39 \%$ of the Calanus (females and Stage V) in the lowest net contained any food and most of these $(29 \%$ of the total) only a very small quantity. In the water in which they were caught these copepods were apparently unable to obtain enough food to maintain themselves. If the observations of 1950 were not all made on occasions when the behaviour of Calanus was abnormal, and obvious vertical migrations do not take place over long periods, it may yet be possible that although the population was not migrating up to, and down from, the rich surface layers all together as it does when the copepods display normal migratory behaviour, it was in a continuous state of flux, some Calanus migrating upwards to feed and others downwards out of the rich water at all times of the day. What stimuli would induce these movements in the individual Calanus is difficult to say unless they are hunger and repletion. In the absence of such movement, a considerable 
fraction of the population apparently remained in deep water where the copepods in time would starve.

Secondly, on most occasions in I95I vertical migration was clearly marked and the copepods spent the daylight hours in deep water, below the strata where food is abundant. In previous work (Gauld, I95I) I was able to show that Calanus was able to filter about $80 \mathrm{ml}$. in $24 \mathrm{hr}$., and the amount of food required by Calanus in $24 \mathrm{hr}$. has been estimated as $0.002-0.013 \mathrm{mg}$. (dry weight) (Marshall et al., I935). If the vertical migration is taking place, this amount of food must be collected not in $24 \mathrm{hr}$., but during the hours of darkness only, i.e. in 8- $\mathrm{I} 2 \mathrm{hr}$., depending on the season, and must be present not in $80 \mathrm{ml}$. but in $30-40 \mathrm{ml}$. of sea water.

\section{SUMMARY}

Records were made of the presence or absence of food in the guts of Calanus finmarchicus caught in three different depths, at intervals of $4 \mathrm{hr}$. through $24 \mathrm{hr}$.

It was found that $80-100 \%$ of the Calanus caught at the surface were full of food at all hours of the day.

The number of Calanus containing food in deeper water was distinctly less. This may be correlated with the abundance of its food close to the surface.

Diurnal vertical migrations took place on some occasions when samples were taken, but not on all.

In the absence of vertical migration Calanus was abundant at the surface and feeding continuously at all hours of the $24 \mathrm{hr}$. Where vertical migration took place feeding was mostly at the surface and was restricted to the hours of darkness, i.e. in summer to a period distinctly less than $8 \mathrm{hr}$. round midnight.

Laboratory observations confirm the absence of any feeding rhythm.

\section{REFERENCES}

BARNES, H., I95I. Horizontal plankton hauls. Fourn. Conseil. Int. Explor. Mer, Vol. 17, pp. 133-9.

BRook, G., I886. Report on the herring fishery of Loch Fyne and the adjacent districts during 1885. 4th Ann. Rep. Fish. Board for Scotland, Appendix F, pt. III, pp. 47-6r.

FULLER, J. L., I937. The feeding rate of Calanus finmarchicus in relation to environmental conditions. Biol. Bull. Woods Hole, Vol. 72, pp. 233-46.

GAuld, D. T., I95I. The grazing rate of planktonic copepods. Fourn. Mar. Biol. Assoc., Vol. 29, pp. 695-706.

Marshall, S. M., Nicholls, A. G. \& OrR, A. P., I934. On the biology of Calanus finmarchicus. V. Seasonal distribution, size, weight and chemical composition in Loch Striven in 1933, and their relation to the phytoplankton. Fourn. Mar. Biol: Assoc., Vol. 19, pp. 793-827.

- 1935. On the biology of Calanus finmarchicus. VI. Oxygen consumption in relation to environmental condition. Fourn. Mar. Biol. Assoc., Vol. 20, pp. I-27. 
MARShall, S. M. \& ORR, A. P., I927. The relation of the plankton to some chemical and physical factors in the Clyde Sea Area. Fourn. Mar. Biol. Assoc., Vol. I4, pp. $837-68$. production. Fourn. Mar. Biol. Assoc., Vol. 30, pp. 527-48.

Nicholls, A. G., I933. On the biology of Calanus finmarchicus. III. Vertical distribution and diurnal migration in the Clyde Sea Area. Fourn. Mar. Biol. Assoc., Vol. I9, pp. 139-64.

REES, C. B., I949. Continuous plankton records: the distribution of Calanus finmarchicus and its two forms in the North Sea, 1938-1939. Hull Bull. Mar. Ecol., Vol. 2, pp. 215-75.

WimpenNy, R. S., 1937. The distribution and feeding of some important plankton organisms in the south western North Sea in I934. Pt. I. Calanus finmarchicus (Gunn.), Sagitta setosa (J. Müller) and S. elegans (Verrill). Min. Agric. Fish. Sci. Invest., Ser. II, Vol. XV, No. 3.

- 1938. Diurnal variation in the feeding and breeding of zooplankton related to the numerical balance of the zoo-phytoplankton community. Fourn. Conseil Int. Explor. Mer, Vol. 13, pp. 323-37. 